\title{
Research and Application of New Teaching Model in Higher Vocational Education Based on "Internet Plus"
}

\author{
Jun Zhao \\ Wuhan Railway Vocational College of Technology \\ Wuhan 430205 China
}

\begin{abstract}
The fundamental purpose of higher vocational education is to train high-quality technical application talents to meet the market's overall demand for talents. The advent of the "Internet plus" era has brought unprecedented opportunities for the development of higher vocational education and the innovation of school-running models. On the basis of expounding of the current situations and emerging challenges of traditional teaching classrooms in higher vocational colleges, this paper analyzes and summarizes the opportunities and optimization of teaching model faced by higher vocational education under the background of "Internet plus", and elaborates the new mode of higher vocational teaching types such as micro-curriculum, massive open online course (MOOC), and reverse classroom. Applying the new "Internet plus" teaching model to higher vocational education is helpful for timely answering the confusion in student learning, promptly motivating students to maintain their enthusiasm for learning, enhance students' subjectivity in the teaching process, and promote the relationship between teachers and students, and improve teaching quality.
\end{abstract}

Keywords-Internet Plus; Higher Vocational Education; New Teaching model

\section{INTRODUCTION}

Vocational education aims to cultivate professional skills and emphasizes skill operation. In order to meet the needs of vocational education and training talents, higher vocational education must be different from traditional higher education goals. Therefore, in the construction of higher vocational education curriculum, the emphasis is placed on students, and the teaching model shifts from teaching to learning are centered. At the same time, teaching ideas and teaching methods are also required to meet the learning habits and behavior habits of modern students. With the advent of the mobile Internet era, students have made major changes in the ways and means of acquiring knowledge and participating in learning. At present, the network and various mobile terminal devices are gradually popularized in society and widely used by people. The way of using mobile devices to communicate and learn anytime and anywhere has become an indispensable part of the daily life of the public, especially young students [1].

The advent of the Internet era has brought about a significant shift in the way of social and economic development, which has had a profound impact on education.
In the context of the Internet, higher vocational education is entering a revolution based on information technology, and information technology have put forward new requirements for higher vocational education. The higher vocational education based on "Internet plus" refers that teachers and students utilize the Internet curriculum space, Internet mobile terminals, and Internet teaching platform to choose their favorite courses, learning environment, or teaching style to cocomplete the education contents; in this model, the inter-class, inter-school sharing and credit recognition are also achieved [2]. On the basis of expounding of the current situations and emerging challenges of traditional teaching classrooms in higher vocational colleges, this paper analyzes and summarizes the opportunities and optimization of teaching model faced by higher vocational education under the background of "Internet plus", elaborates the New mode of higher vocational teaching types such as micro-curriculum, massive open online course (MOOC), and reverse classroom, and explores the new mode of education based on the optimization of teaching objectives, the reconstruction of classroom teaching model in the "Internet plus" era.

\section{II. “INTERNET PLUS” NeW MODE OF Higher VocATIONAL TEACHING}

Aiming at the training goal of vocational education talents, paying attention to the characteristics of technical skills training, the teaching model should also be more in line with the characteristics of vocational education, and the cultivation of talents should be more targeted. Through daily teaching practice and preliminary investigation and research, Internet teaching resources are rich, and there are many resources available. However, for vocational education, many resources are not really applicable to vocational education and teaching, and in order to enrich the online education resources of vocational education, simply create a massive open online course (MOOC). Methods such as micro-courses may not be fully applicable. Vocational education is different from basic education. It is clearer about job breakdown, and the job requirements are more professional. Relatively speaking, the training process is more targeted. The overly broad curriculum cannot meet the requirements of vocational education for talent training. Therefore, through research, using the "Internet plus" thinking mode, integrating online and offline resources, using a series of technologies such as mobile internet, data 
analysis, and sorting, and seeking effective ways to obtain a more suitable teaching model for vocational education [3] .

The learning statistics function on the platform can count each student's learning progress, learning behavior trajectory, homework score, and participation in the number of discussions, etc., to better help teachers control the learning progress and monitor the learning results. The Internet-based hybrid collaborative learning model is shown in Fig. 1. Teachers can clearly see how long each student stays in a certain knowledge unit, and repeatedly read back several times answer a few questions, etc., according to which students can understand how difficult it is to learn and timely Provide feedback and guidance online. Students can also use the platform to learn and communicate with each other to understand each other's gains and questions. Teachers will check the students' learning before the classroom and organize offline classroom activities according to the online learning situation. Learning evaluation is a process of evaluating learners' learning processes and outcomes and making value judgments for learners' learning. The "Internet plus" teaching model achieves an organic combination of procedural and summative evaluation, online and offline evaluation, learning behavior and evaluation of learning outcomes [4].

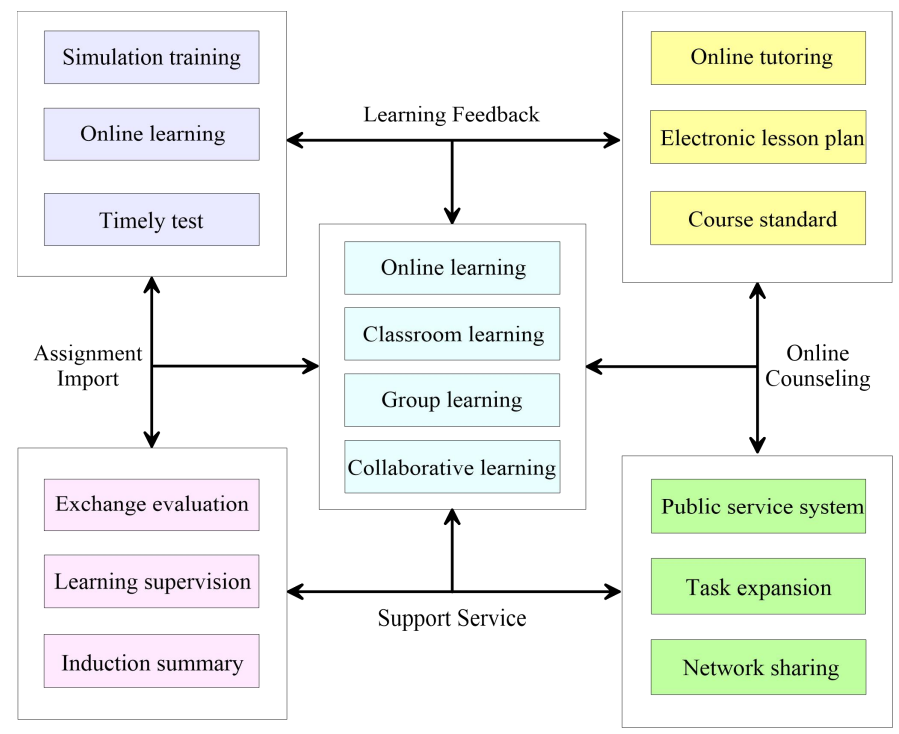

Fig. 1. Internet-based hybrid collaborative learning model

Construct an evaluation system for English teaching in a network environment. In traditional teaching, the final evaluation of English teaching in higher vocational schools is the main evaluation system of English teaching, and the test scores are often used as the sole criterion for testing students' English knowledge ability. With the advent of the network era, English education is constantly innovating and reforming. It is gradually breaking the traditional teaching evaluation system and establishing an evaluation system that conforms to the characteristics of English classroom teaching under the network environment. It will form formative evaluation, summative evaluation and students. This kind of teaching evaluation system uses information technology to collect, analyze and process students' learning behavior records and learning data in a timely manner, and through objective analysis, it makes an objective, fair and comprehensive evaluation of students' knowledge ability.

Students are the main body of the teaching process. In the traditional high-level classroom teaching activities, teachers often talk too much, and there are too few interactions with students [5]. Even in classrooms with more interaction with students, students still answer questions from teachers. The traditional vocational classroom teaching only pays attention to the teacher's teaching and neglects the students' learning. The leading role of the teacher becomes a decisive role. The student's main role cannot be fully reflected, which ultimately suppresses the students' wisdom and talents and limits the students. In preparing the lesson, teachers not only need to prepare the class content, but also prepare students. This problem has been repeatedly emphasized for many years, but in the process of implementation, teachers often ignore the students' feelings, prepare more lessons than students, and pay more attention to how to the content of the class is clearly explained. Teachers spend a lot of energy on preparing for the class, the teaching effect is very general, and the students can digest the limited knowledge. The comparison of analytical parameters between traditional classroom and "Internet plus" classroom in higher vocational education is shown in Fig. 2.

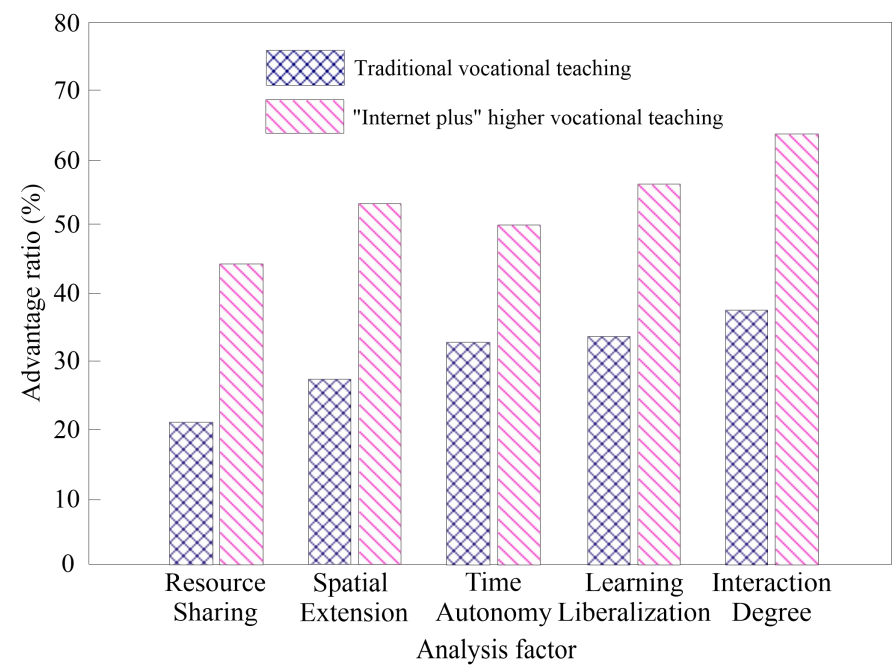

Fig. 2. Comparison of analytical parameters between the traditiona classroom and the "Internet plus" classroom in higher vocational education

In the process of flipping the classroom teaching model, if the teacher does not make sufficient preparatory work and does not organize the pre-class study, the teaching under the class will be inefficient or even difficult to implement. Therefore, in the practice of flipping classrooms, we can not rely on mechanical human-computer communication, but need to inject more humanistic care, and achieve personalized implementation of flipping classrooms. For example, on the one hand, analyzing and studying the differences in learning ability of higher vocational students, providing more Easy-tounderstand learning situations and results cases; on the other hand, emphasize and improve teachers to create a good interactive atmosphere in teaching, promote the emotional exchange between teachers and students, and exercise students' communication and communication skills, so that the 
lively and healthy interpersonal relationship between the two sides continues to develop.

"Internet plus" vocational education strive to realize personalized, decentralized and networked individual education that is compatible with the future ecological civilization through the Internet. Based on the Internet, all learning processes, learning evaluations and learning effects of learners can pass data. Forms for record analysis, mixed learning and cooperative learning will become the mainstream based on the Internet, teachers pay more attention to cultivating their own positive awareness of networked teaching, and then use modern teaching methods to improve the quality of personnel training, the role of one-way instilling knowledge will occur a major shift; based on the Internet, with the characteristics of big data, cloud computing, mobile internet and free use, it will break the imbalance between geography, urban and rural areas, and make more learners with more learning needs more fair.

\section{APPLICATION OF "INTERNET PLUS" IN HIGHER VOCATIONAL TEACHING}

The traditional campus teaching of mechanical majors can be directly supported by powerful hardware. For example, training students to practice hands-on courses can help students to learn and practice, and help students to master from theory to practice. It is also necessary to let students master some professional cutting-edge technical courses and professional theoretical courses, which is the professional teaching goal, so that the superimposed teaching model will be adopted in the context of "Internet plus", that is, the MOOC and micro-course online teaching model. With the teaching model such as on-site practice, traditional teaching such as teaching process and teacher-student relationship is reconstructed.

The new teaching model transcends the traditional model of the past. It has built a teaching platform supported by information technology, which has changed the old model of teacher-led teaching and passive mechanical learning. Table 1 shows the proportion of roles and their functions in the new "Internet plus"-based teaching model of higher vocational education. The emergence of new models has made the teaching reform of English subjects deeper. The application of "Internet plus" to higher vocational English teaching can create a more specific and vivid language environment for students. Teachers use modern information technology to simulate real life scenes in the classroom, create a certain language environment suitable for vocational teaching, and stimulate the potential of learners to practice English, and promote learners to actively participate in public classroom learning. Going, fundamentally improve the teaching efficiency of the public classroom [6].

TABLE I. THE PROPORTION OF ROLES AND THEIR FUNCTIONS IN THE NEW “INTERNET PLUS”-BASED TEACHING MODEL OF HIGHER VOCATIONAL EDUCATION

\begin{tabular}{|c|c|c|c|c|c|c|}
\hline & Object & Course study & Interactive learning & Exchange learning & Information sharing & Knowledge mastery \\
\hline \multirow{5}{*}{ Role } & Course builder & $17.4 \%$ & $23.6 \%$ & $37.5 \%$ & $10.4 \%$ & $10.8 \%$ \\
\hline & Teacher & $14.1 \%$ & $25.2 \%$ & $19.7 \%$ & $28.4 \%$ & $12.6 \%$ \\
\hline & Student & $0.08 \%$ & $28.9 \%$ & $14.8 \%$ & $33.8 \%$ & $22.6 \%$ \\
\hline & Alumni & $27.1 \%$ & $14.5 \%$ & $3.37 \%$ & $10.4 \%$ & $44.9 \%$ \\
\hline & Researcher & $11.2 \%$ & $29.4 \%$ & $18.5 \%$ & $27.2 \%$ & $13.7 \%$ \\
\hline \multirow{5}{*}{ Function } & Interactive learning & $31.6 \%$ & $0.08 \%$ & $25.4 \%$ & $17.6 \%$ & $25.5 \%$ \\
\hline & Interactive teaching & $16.3 \%$ & $20.0 \%$ & $15.9 \%$ & $31.6 \%$ & $16.2 \%$ \\
\hline & Cloud storage & $22.2 \%$ & $14.9 \%$ & $26.2 \%$ & $10.4 \%$ & $26.3 \%$ \\
\hline & Real-time feedback & $17.6 \%$ & $12.3 \%$ & $48.5 \%$ & $0.10 \%$ & $31.5 \%$ \\
\hline & Online evaluation & $10.5 \%$ & $27.1 \%$ & $23.0 \%$ & $32.8 \%$ & $6.60 \%$ \\
\hline \multirow{5}{*}{ Activity } & Class discussion & $21.1 \%$ & $34.1 \%$ & $10.6 \%$ & $25.3 \%$ & $8.90 \%$ \\
\hline & Classroom simulation & $13.7 \%$ & $25.7 \%$ & $19.4 \%$ & $26.1 \%$ & $15.1 \%$ \\
\hline & Mutual help & $31.1 \%$ & $16.3 \%$ & $25.3 \%$ & $10.7 \%$ & $44.6 \%$ \\
\hline & Scene establishment & $21.4 \%$ & $19.2 \%$ & $20.5 \%$ & $25.2 \%$ & $13.7 \%$ \\
\hline & Society activity & $14.1 \%$ & $22.2 \%$ & $12.9 \%$ & $33.6 \%$ & $16.2 \%$ \\
\hline
\end{tabular}

Teachers should make full use of the advantages of modern science and technology, through careful study, combined with the characteristics of the teaching department, introduce new technology into the classroom, and facilitate their daily teaching through practical application, so that students have a new experience. Students pass their respective student and initialization passwords to the system to test their daily learning, and to review and summarize the phased learning to understand their knowledge. After the students log in to the practice and test platform, they are completed and submitted within limited time according to the questions randomly assigned by the system. After the test is over, the teacher will use the background terminal to review the papers and give targeted feedback according to the students' answers. Help the students to conduct error analysis, clarify the knowledge points and context system, and give rationalization suggestions for improving and improving students' future learning [7].

Compared with traditional curriculum teaching, the new "Internet plus" teaching technology is different from the formal differences in teaching methods and teaching design principles. The "Internet plus" teaching new technology teaching design is the process of selecting teaching content and learning resources according to the objectives, determining the organizational structure of the curriculum, and implementing the curriculum. It mainly includes the organization and design of teaching resources, the design of teaching activities and the design of learning evaluation. It is a student, teacher, industry enterprise expert teacher, manager, alumni, student parents, etc. The carrier of activities such as communication, sharing, communication, reflection, 
expression, and inheritance between subjects, supports a learner's personalized learning and encourages a network virtual learning environment for interaction between learners. It is capable of storing knowledge and sharing.

\section{ThOUGHTS ON "INTERNET PLUS" ClassRoOM TEACHING}

The Internet-based hybrid collaborative learning model is a teaching model based on the characteristics of two learning modes based on "mixed learning" and "collaborative learning". It combines the advantages of traditional classroom learning with the online collaborative learning of computers. Students use a variety of learning elements under the guidance of teachers to conduct classroom learning and collaborative learning around the learning objectives in the form of "collaborative" learning groups. The learning mode not only breaks the time and space boundaries of traditional teaching, but also fully embodies the idea of "teaching equal emphasis", which helps to cultivate students' independent learning ability, innovative ability and hands-on practical ability. It can be seen that the effective application of it to curriculum teaching can give full play to the advantages of classroom teaching and online learning, and it is necessary to meet the new requirements of the information society for talent training.

In the information age, students are more inclined to obtain information through the network platform. At present, due to the limitations of hardware facilities, some higher vocational colleges still carry out classroom teaching in a single teaching environment to a large extent, such as teaching in traditional classrooms and computer rooms. These teaching places lack corporate culture and realities. Production scenes, teaching content is not rich enough, there is still a certain distance between the students' practical operation and the actual requirements corresponding to the corporate positions, and the connection between professional practice learning and actual job work cannot be realized, which makes it difficult for some students to be competent in future jobs.

\section{CONCLUSIONS}

The "Internet plus" era is both an opportunity and a challenge for the overall education of higher vocational colleges. In order to meet the overall needs of talents in the modern social market, higher vocational colleges need to keep pace with the times, reform and Innovative education teaching model, on the basis of ensuring the effective improvement of its own teaching quality, lays a good foundation for the development of higher vocational colleges in the context of the "Internet plus" era. In the era of "Internet plus", the teaching model of higher vocational education should be adjusted and innovated. The key is to use the new theory and new concept to user thinking on the basis of the impact of higher education teaching objectives and teaching activities under the background of full-fledged new technology. Being the core, attaching importance to the cultivation of innovative ability, optimizing the educational and teaching objectives of high-quality technical and skilled talents, with this goal as the guide, emphasizing the subjective and teacher-led classroom teaching concepts, using online courses, online teaching videos, virtual simulations Rich teaching resources, design and reconstruction of new educational teaching model.

\section{REFERENCES}

[1] Liu B. Construction of blended teaching model based on "Internet plus" -Taking higher vocational business English teaching as an example. Journal of Hunan Post and Telecommunication College, 2017, 16(4): 126-129.

[2] Feng Y.Z. Reflection and prospect of MOOC + SPOC online courses in higher vocational English teaching. Journal of Heilongjiang College of Education, 2018, 27(11): 62-64.

[3] Xie D. On the construction of English teaching resources in higher vocational colleges in the era of "Internet plus" from the perspective of ecopedagogy.

[4] Zhang Y. A probe into an "Internet +"-based EOP teaching model for vocational colleges. Computer-assisted Language Education, 2016, 168: 75-80.

[5] Fu X.J. Study on flipped classroom model for higher vocational education under Internet plus situation-Take network marketing practice as an example. Bulletin of Science and Technology, 2017, 33(10): 248-251.

[6] Cheng C. Strategies on promoting the mixed teaching model of higher vocational education. Advanced Engineering Forum, 2012, 6-7: 11951198 .

[7] Wang Q.Q. Research on the application of experiential teaching model in higher vocational English teaching in the era of "Internet +". Shipbuilding Vocational Education, 2017, 5(5): 12-15. 